\title{
Mesa redonda \\ As estratégias e instrumentos de inclusão social e os direitos das pessoas com transtornos mentais em conflito com a lei
}

\author{
Programa de atenção integral ao paciente judiciário portador de sofrimento mental \\ (PAI-PJ) Minas Gerais \\ Dr. a Romina M. de Magalhães Gomes \\ A experiência italiana do fechamento de hospitais psiquiátricos judiciais \\ Dra Giovanna del Giudice \\ Programa de atenção integral ao louco infrator (PAILI) \\ Dr. Haroldo Caetano da Silva
}

\section{SciELO Books / SciELO Livros / SciELO Libros}

GOMES, R.M.M., GIUDICE, G., and SILVA, H.C. As estratégias e instrumentos de inclusão social e os direitos das pessoas com transtornos mentais em conflito com a lei. In: BARROS, S., BATISTA, L.E., and SANTOS, J.C., comps. Saúde mental e reabilitação psicossocial: avanços e desafios nos 15 anos da Lei 10.2016 [online]. Uberlândia: Navegando Publicações, 2019, pp. 89-112. ISBN: 978-65-8141707-9. https://doi.org/10.7476/9786581417079.0006. Transcrição dos Anais do II Encontro de Saúde Mental - Reabilitação Psicossocial: avanços e desafios 15 anos após a Lei 10.216, Uberlândia, MG, 2016.

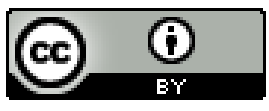

All the contents of this work, except where otherwise noted, is licensed under a Creative Commons Attribution 4.0 International license.

Todo o conteúdo deste trabalho, exceto quando houver ressalva, é publicado sob a licença Creative Commons Atribição 4.0.

Todo el contenido de esta obra, excepto donde se indique lo contrario, está bajo licencia de la licencia $\underline{\text { Creative }}$ Commons Reconocimento 4.0. 


\section{Mesa redonda - As estratégias e instrumentos de inclusão social e os direitos das pessoas com transtornos mentais em conflito com a lei}

Coordenação: Prof. Dr. Jandro Moraes Cortes - Enfermeiro, Professor Doutor do Departamento de Enfermagem Materno-Infantil e Psiquiátrica da Escola de Enfermagem da USP.

\section{Programa de atenção integral ao paciente judiciário portador de sofrimento mental (PAI- PJ) Minas Gerais - Dr. ${ }^{a}$ Romina M. de Magalhães Gomes}

Psicóloga Judicial do Núcleo Supervisor do Programa de Atenção Integral ao Paciente Judiciário (PAI-PJ) vinculado ao Tribunal de Justiça do Estado de Minas Gerais, Doutora em Psicologia pela Universidade Federal de Minas Gerais.

Boa tarde a todos e todas. Eu gostaria de agradecer em primeiro lugar à doutora Sônia Barros pelo convite para estar aqui hoje. É com muita satisfação que eu tenho falado um pouco do programa de atenção integral ao paciente judiciário do tribunal de justiça de Minas Gerais. Eu gostaria de parabenizá- los por esse encontro, pela iniciativa de colocar em discussão esse tema em um momento tão delicado pelo qual passa o nosso país, pois nós nos encontramos à beira de um imenso retrocesso. Sobretudo no que se refere às políticas públicas e à manutenção dos serviços de saúde mental.

É um grande desafio avançar quando os recursos encontram-se sob ameaça de serem retirados. Mais do que nunca a gente precisa tornar vivo esse debate, essa discussão. Então, eu pretendo trazer para vocês um pouco da experiência do PAI PJ que é um programa do tribunal de justiça de Minas Gerais sobre o viés da inclusão social e dos direitos das pessoas que apresentam sofrimento mental e que cometeram um ilícito penal. Para alcançar esse objetivo, eu vou retomar brevemente alguns aspectos que se encontram na gênese da medida de segurança, que é a sentença aplicada aos loucos infratores. Para tentar recuperar um pouco a complexidade dessa questão. 
Robert Castel é um autor francês que nos ajuda, ele nos dá algumas pistas para nós iniciarmos essa tarefa de recuperar esses pontos, esses fundamentos que estão na base da medida de segurança. Ao nos apontar que com a invenção do estado moderno, conseguido a partir dos ideais de igualdade e liberdade que alimentaram a revolução francesa, colocou-se a questão de não se poder tomar o louco como igual. O estado moderno se edificou então sobre o sistema contratual por meio do qual os cidadãos foram tomados como soberanos. Mas também, foram tomados então como soberanos, mas também sujeitados aos deveres que deveriam assumir, sob pena de receberem uma sanção repressiva. Ao mesmo tempo, os cidadãos poderiam participar das atividades subordinadas à lei, de onde retirariam os seus direitos que definem a sua liberdade.

Apesar da igualdade de direitos pertencer a uma dimensão puramente formal, considerou-se que determinada categoria de indivíduos não poderia fazer parte, sem problemas, desse sistema contratual. O problema colocado pelo louco se distinguiu por seus crimes não oferecerem nenhum vínculo racional passível de reunir a transgressão das leis à repressão. Se buscava um vínculo que pudesse justificar a repressão, vinculando à transgressão da lei. O que motivou esse sujeito a cometer esse crime? Então, esse vínculo era buscado nos motivos, nas razões do crime. E os crimes cometidos pelos loucos, na virada do século XVIII para o século XIX, na época da revolução francesa, eles eram chamados de crimes imotivados, ou crimes sem razão. Porque eram crimes bárbaros, muito graves, essas pessoas foram muitas vezes tomadas como monstros, porque chegaram a cometer crimes tão graves, e muitas vezes esses crimes atingiam ascendentes ou descendentes, então iam contra a natureza humana. E por esse fato eles começaram a se perguntar quais seriam os motivos e não se via ali um vínculo racional passível de justificar a punição aquelas pessoas.

Então, a solução encontrada, Robert Castel é quem vai nos dizer, a partir da intervenção do discurso psiquiátrico, foi a de submeter o louco ao tratamento, ao invés de submetê-lo a uma pena. Ainda que esse tratamento representasse também uma espécie de penalização. Entretanto, essa sanção só poderia subsistir de modo disfarçado, justificada pela racionalidade terapêutica. O louco foi então retirado do guarda-chuva formal da igualdade de direitos que funda a democracia moderna, e foi então entregue à psiquiatria para realizar a sua gestão.

A psiquiatria, Castel vai focar isso, nasce então em resposta a um problema de governo, para responder a um problema de governo, apesar de ter justificado como estritamente técnica o seu campo de intervenção. Quem vai ocupar esse espaço então, é a psiquiatria que surge com Pinel, a chamada medicina mental, no início, a psiquiatria não 
era chamada como tal, era nomeada medicina mental, e Pinel e seus discípulos irão então propor que o louco deveria alojar em si o mal, ele seria portador de um déficit moral que o tornaria incapaz de responder por não poder controlar a própria vontade, então as suas ações, segundo esses autores, os discípulos de Pinel, seriam determinadas pelo instinto, força irresistível que age no sujeito, em detrimento do que ele possa querer, o instinto seria capaz de se sobrepor e anular toda a vontade produzindo um impulso irresistível ao ato violento, desse modo o louco foi concebido como perigoso devido à imprevisibilidade e a impulsividade que lhe foram atribuídas desde então, partindo do início aí do século XIX, com a formulação de Pinel e seus discípulos até chegar em Lombroso. Essas concepções fizeram com que o poder judiciário recuasse em sua tarefa de convocá-los a esse momento pelos atos cometidos e os entregassem a psiquiatria criminal para realizarem a sua gestão, com a proposta de estabelecer uma vigilância contínua dos loucos; em um espaço vazio a psiquiatria então assumiu esse lugar, de administrar a loucura.

É com a síntese dessas ideias que nasceram com o Pinel, que foi empreendida depois por Lombroso, e a criação da escola criminal positiva, a concepção de uma periculosidade intrínseca ao homem foi difundida, de acordo com essa perspectiva determinista, mecanismos de controle foram criados, visando defesa social, e a precaução contra os riscos envolvidos na convivência com a loucura, a presunção de periculosidade que implica atribuir ao louco infrator um risco virtual futuro, de cometer novas infrações penais fez surgir a ideia de um dispositivo de controle e segregação específico no manicômio judiciário. Aí essas ideias então foram difundidas no Brasil a partir do século XIX, na virada do século XIX para o século XX, alguns autores que se destacaram aí, sobretudo; Nina Rodrigues, Franco da Rocha, Heitor Carrilho, e o sistema de isolamento do louco em manicômios judiciários foi incorporado à legislação. Com o código penal de 1940 surgiu a medida de segurança com o instituto jurídico, no ordenamento jurídico brasileiro, e nessa época, então, já em 1940, a medida de segurança já possuía a característica de ser por tempo indeterminado, ou seja, sem limite temporal, só podendo ser extinta pelo exame de cessação de periculosidade feito pelos peritos psiquiatras.

A história mostra que esse dispositivo jurídico psiquiátrico continuou a permitir o isolamento e a manutenção da sanção penal por tempo indeterminado, e em muitos casos durante toda uma vida, pois os loucos vias de regra, eram tomados como intrinsecamente perigosos.Com a reforma psiquiátrica e o surgimento da luta antimanicomial na década de 1980, no Brasil, os absurdos que aconteciam no âmbito da atenção a loucura começaram a se tornar visíveis e questionados como todos vocês sabem, nós estamos aqui hoje justamente comemorando e tentando avançar nessa questão, passaram então a ser 
amplamente questionados, e a Lei 10.216 veio redirecionar o modelo de tratamento no plano da psiquiatria, mas há ainda um fosso que separa a aplicação dessa lei, e a legislação penal relativa a pessoa em situação de sofrimento psíquico, é o que programas como o Pai-PJ tentam tratar, cuidar dessa questão para tentar diminuir esse fosso e tentar levar a lei 10.216 para ojudiciário.

Bom, isso se repete, não só esse fosso que existe entre a legislação penal e a lei 10.216, se repete também com relação a Constituição Federal e a Legislação Penal, cujos preceitos são continuamente ignorados e desrespeitados, no que diz desrespeito a aplicação da medida de segurança, o princípio constitucional da dignidade da pessoa humana é continuamente ferido com a aplicação dessa sanção penal, sobretudo, devido a essa etiqueta de perigoso que nasce lá no século XIX a partir do surgimento da medicina mental, essa seria, vamos dizer assim, a pior, a mais cruel, e equivocada nomeação que poderia ser dada a alguém, essa de perigoso, outra nomeação que frequentemente lhe é atrelada, que o doutor Jefferson recuperou aqui hoje de manhã para nós, é a de incapacidade, é tão nefasta quanto, e que os próprios portadores de sofrimento mental recusam, se a gente for lá nos sanatórios, nas conferências de saúde mental, a última conferência de saúde mental, a gente vai ver essa recusa, isso foi registrado no relatório dessas nomeações de perigoso e de incapaz. Então, todas essas nomeações apontam para um desprezo da palavra, da pessoa em situação de sofrimento psíquico submetida a sanção penal.

Podemos falar nesses casos em igualdade de direitos? Em dignidade da pessoa humana?

A lei 10.216 vem permitir, dentre outras coisas, que reconheçamos todos que a internação por tempo indeterminado, e muitas vezes perpétua, representa uma incomensurável violência aos direitos fundamentais dos portadores de sofrimento mental. Então, eu vou passar a proposta do Pai-PJ, tentar mostrar para vocês qual seria essa alternativa que é proposta pelo programa de atenção integral de paciente judiciário, como é que se aborda essa questão da periculosidade, da incapacidade, da inimputabilidade, que seria de certo modo considerado como incapaz de responder pelos seus atos, inclusive os atos que resultam em processo criminal, então eu vou procurar mostrar para vocês um pouco do que é esse trabalho.

O Pai-PJ surge a partir de uma pesquisa realizada pela Fernanda Otoni, que é uma psicóloga judicial, psicanalista, professora universitária, que em 1999 iniciou uma pesquisa com relação a esses casos, que eram submetidos a certeza da medida de segurança, e a partir desse projeto de pesquisa em 2000 foi proposto um projeto piloto que começou, 
então, um acompanhamento de casos, na comarca de Belo Horizonte. Esse projeto ele começa em um momento em que Belo Horizonte passava pela reforma psiquiátrica, pela substituição dos serviços de saúde mental, criação dos CAPS, e lá nós temos a nomeação do CERSAM; então os hospitais psiquiátricos começaram a receber casos apenas daqueles lugares em que ainda não haviam CAPS, não tinham ainda uma rede estruturada, que não podiam então oferecer um tratamento de crise, ao passo que os juízes começaram a determinar, por falta de vaga em manicômios judiciários, a internação dessas pessoas que recebiam a sentença de medida de segurança, que cometeram um crime e tinham sofrimento mental, começaram a determinar que essas pessoas fossem para os hospitais públicos psiquiátricos, e isso gerou uma grande crise, um grande descompasso, e nesse momento dessa crise então, surge a proposta desse programa que vai então tratar de um modo distinto, dessa questão. Desde 1995 em Minas Gerais, existiu a lei 11.802 que é a chamada lei Carlão, que é a lei da reforma psiquiátrica estadual de Minas Gerais, então a partir desse momento os serviços substitutivos já existiam, toda a política estava sendo redirecionada, em 2001, juntamente com a lei 10.216, o Pai-PJ então se tornou um programa, porque até então era um projeto piloto, mas era um programa restrito a comarca de Belo Horizonte.

No ano de 2010 o Tribunal de Justiça entendendo que essa política deveria abranger todo o estado de Minas Gerais criou a resolução 633 que passou a regulamentar o trabalho que programa no estado de Mina Gerais, dentro desta resolução existe a definição do que é o público do programa Pai-PJ, então nós encontramos lá no artigo $7^{\circ}$ da resolução 633 o que é um paciente judiciário; seria então qualquer pessoa em situação de sofrimento psíquico que seja indiciado, réu, ou sentenciado em processo criminal, ou adolescente autor de ato infracional, esse é o público do programa. Se a gente for olhar assim, a gente pensa que é muito amplo, as pessoas muitas vezes confundem um pouco, pensam no conceito ampliado, o que é o sofrimento psíquico, a gente tende a restringir aos casos de psicose, que tem esquizofrenia, transtorno bipolar, então são aqueles casos muito graves da saúde mental, o público dos CAPS, que são pacientes do Pai-PJ.

Qual que é a função do programa?

A Fernanda Otoni propõe que a função primordial do programa é de ser um dispositivo conector, que articula os diversos setores envolvidos na atenção ao público infrator visando promover sua inserção social, a sua responsabilização, e o seu tratamento, além disso o programa auxilia juízes criminais informando sobre o cumprimento da medida de segurança, possibilitando a sua individualização, sempre considerando a singularidade de cada caso. 
A equipe do programa é composta por psicólogos, assistente sociais, e assistentes jurídicos, essa equipe tem a função primordial de acompanhar os casos privilegiando a escuta do detalhe próprio a cada sujeito, e articular as redes de atenção orientados sempre pela singularidade de cada um. Eu vou passar a falar sobre os princípios orientadores deste trabalho, porque eu acho que é fundamental trazer um pouco para vocês o que é que nos orienta, e vai fazer um gancho com aquelas ideias que eu trouxe no início com a introdução, vocês vão entender como que o Pai-PJ se posiciona com relação a essas várias construções que fazem parte hoje do imaginário social; o primeiro deles diz respeito a questão da periculosidade, no lugar de presunção de periculosidade a proposta do programa é a presunção de sociabilidade, o que seria isso? Seria então tentar subverter a presunção de periculosidade e das práticas de segregação, o estabelecimento de uma nova política no campo da saúde mental, com a implantação dos serviços substitutivos ao manicômio, permitiu que essa proposta fosseconcretizada.

O grande desafio para nós, o tempo inteiro, é de abrir espaço no tecido social para fazer caber as diferenças, porque existe um imaginário social de que essas pessoas que cometem crimes muito graves, elas tem que ser segregadas, elas são de fato perigosas, elas são de fato imprevisíveis, impulsivas, então a resposta a isso seria a segregação, ao passo que quando a gente começa a ver de perto os casos, conhecer cada sujeito, poder falar, a própria rede às vezes recebe com um certo temor, como que a gente vai receber esses casos que cometeram crimes tão graves, o que é que essa pessoa pode fazer aqui dentro, então quando se começa a falar sobre os casos a coisa se desloca e as pessoas começam a perceber que se trata de uma pessoa em sofrimento como outra qualquer. O segundo princípio orientador é a questão da responsabilidade, seria também uma subversão da inimputabilidade e da incapacidade de resposta que foram atribuídas ao louco infrator pelo direito e pela a psiquiatria; nós consideramos, então, que todo o ser falante, todo sujeito é capaz de responder, é capaz de inventar algo para tratar o seu sofrimento, essa é a resposta que o programa busca, eu coloquei ali uma referência a um psicanalista, que é o Jacque Lacan, que vai trabalhar a questão da responsabilidade na loucura, não sei se vocês já tiveram a oportunidade de ter contato com o seminário vinte e três, do Lacan, não é um livro exatamente muito fácil, mas vale a pena a gente perceber como que o Lacan aborda e nos mostra ser possível pensar a loucura como responsável, porque todo mundo responde ao sofrimento, todo mundo elabora uma resposta ao encontro com a angústia, com o que faz sofrer, e os outros não seriam diferentes, todo ser humano é capaz de resposta.

O Terceiro princípio orientador, é um tratamento orientado pelas singularidades, é fundamental, esse é o eixo do programa, cada sujeito com suas peculiaridades, com o seu 
modo único de responder ao mundo e ao outro orienta o tratamento; essa metodologia operam uma subversão para a abordagem do sofrimento mental feita pelo viés da psicopatologia, as invenções de cada sujeito para tratar o sofrimento são elevadas a agilidade de uma orientação no tratamento. O quarto princípio eu vou correr um pouco porque já está terminando o tempo, depois a gente pode ter tempo para conversar, o trabalho em rede, fundamental para o nosso trabalho, Pai-PJ só existe porque existe uma rede de saúde mental estruturada, no Brasil, ou digamos assim em processo de estruturação, e a gente trabalha juntamente com essa rede, com uma parte dessa rede, então essa prática é feita com muitos que se dispõem a deixar de lado o seu saber especializado para se orientar pelo saber do sujeito.

O trabalho acontece em rede com sua horizontalidade, diferente de um trabalho hierarquizado, um saber acima de outro, e por cima do outro, é a rede como vocês sabem, ela funciona em uma horizontalidade com várias entradas possíveis, e é a rede que é tecida pelo sujeito. Isso faz toda a diferença, o que é a rede de saúde mental para um determinado sujeito, é a rede que ele teceu, então a gente às vezes cria um serviço, abre a porta, e chama o sujeito, e convida ele a se adaptar ao que a gente propõe, não é bem essa a proposta, porque a gente começou a perceber que essa questão da adaptação do sujeito ao serviço não trata exatamente do que a gente estava desejando propor, então a gente é que vai tentar chegar nesse sujeito com uma oferta de algo que faça sentido para ele, que possa provocar um vínculo, nós é que vamos atrás desse sujeito, vamos correr atrás, então não é o sujeito que vai aderir, é nós que vamos aderir a ele, então a gente é que vai tentar produzir aí essa rede de acordo com que ele está acoplado. E, essa rede ela inclui, a saúde mental, ela inclui a justiça, o juiz passa a fazer parte dessa rede, a defensoria pública, a promotoria, as diversas ofertas que uma cidade pode fazer no campo do trabalho, de cursos profissionalizantes, então é uma rede a mais ampliada possível segundo o que cada sujeito aponta. E o quinto princípio orientador é o ato jurídico como operador clínico, essa foi uma grande descoberta da Fernanda Otoni desde o início do programa, ela começa a perceber, que as pessoas tem um certo endereçamento a justiça, que supõem que a justiça vá ajudá-los a regular o seu sofrimento, a tratar o que está fazendo sofrer, então a gente valoriza esse ponto aí da vinculação a justiça, o tratamento então por se articular ao ordenamento jurídico abre a possibilidade de recurso as ficções jurídicas, a convocação do sujeito para responder pelo seu ato fora da lei não é sem consequências, quando ele percebe um chamado da justiça, quando um cidadão em sofrimento mental recebe um chamado da justiça ele, o que a gente vê assim na grande maioria dos casos, é uma prontidão em responder, "Ah, o juiz me chamou, o promotor está dizendo para eu tratar ", etc, passam então a responder esse chamado, a construir uma resposta 
orientada pela lei, as menções jurídicas podem então funcionar como operador clínico, favorecendo a estabilização, e a construção de novas respostas que são compatíveis com o laço social, isso faz toda a diferença em um programa como Pai-PJ.

Eu não sei se dá tempo de eu, estou com alguns fragmentos de casos, vou passar um ou dois rapidinho aqui, só para vocês terem ideia, o que é esse lugar que essas pessoas atribuem a justiça, ao direito, e se torna então um recurso, um recurso que auxilie no seu tratamento, o direito como parceiro do sujeito, o campo da justiça se torna então o lugar privilegiado de para os pacientes judiciários que vivenciam o caos subjetivo, a função reguladora do direito destaca-se de modo contundente no acompanhamento de pacientes judiciários pelo Pai-PJ, podendo produzir uma orientação para o sujeito que se encontra acossado por intensa angústia e sofrimento.

Um fragmento de caso; A oferta de acompanhamento pelo Pai-PJ, faz com que João vire frequentemente para a técnica de referência do programa para contar que teve a sua pele roubada, essa é uma queixa constante desse paciente que se manteve em sofrimento corporal, o tempo todo falando que estava sem costela, minha pele foi roubada, cadê a pele do Rambo assim, muito delirante com essa questão e muito angustiado, com passagens ao muito grave, então ele passa a ligar para o programa e isso se torna um recurso, ele vai lá conversar, se queixar, pedindo para que a justiça tome providências. Isso produz para esse sujeito um certo apaziguamento.

Para Carlos, outro paciente acompanhado pelo programa, levar relatórios que comprovam seu tratamento para anexar ao processo em função decisiva, ele faz questão de levar, porque ele quer mostrar para o juiz como que ele tá cumprindo a sentença que ele recebeu, e o juiz passa então a fazer parte dessa rede para esse sujeito. Luiz encontrava-se em situação de crise, tendo passado por várias internações, é um caso que, desde de lá do começo Pai-PJ, anteriormente a ascensão do programa, ele tinha esse histórico de várias internações, e ele estabiliza quando alguém testemunha diante do juiz, que ele era um bom rapaz, ele merecia uma chance porque ele era um bom rapaz, então nessa ocasião ele deixa o tráfico de drogas, ele se nomeava de matador, ele falava que tinha matado sete pessoas, era um traficante considerado perigoso e tudo, então ele deixa de usar drogas, deixa o tráfico, e vai então começar a cuidar das pessoas da sua família que precisavam de cuidados, que fazem tratamentos de saúde etc, e ele estabiliza a partir dessa ocasião, desse testemunho diante do juiz, isso passa a valer para ele como uma orientação. Bom, tem vários casos, acho que eu vou parar por aqui, eu vou só falar um pouco para vocês de alguns resultados, hoje nós temos 1700 casos mapeados em Minas Gerais, a gente não está no momento atendendo todo o estado de Minas Gerais por um 
problema da gestão anterior do Tribunal de Justiça, mas a atual gestão está reestruturando o programa, nós não sabemos ainda quando que vai ser possível voltar ao interior do estado, no momento a gente está na região da grande Belo Horizonte, mas nós temos então mapeados 1700 casos, 6000 casos já passaram pelo programa, o tempo médio de permanência é de cinco anos, e a reincidência dois por cento. Tem aí o contato, tem o site do Tribunal de Justiça, tem o site da Revista Responsabilidades quem desejar dá uma olhada tem vários artigos, têm uma monografia que foi premiada da Fernanda Otoni, está inteiramente disponível lá na página da revista, todos os números estão integralmente disponíveis on line, quem desejar dá uma olhada.

Então é isso gente, muito obrigada.

\section{A experiência italiana do fechamento de hospitais psiquiátricos judiciais - $\mathrm{Dr}^{\mathrm{a}}$ Giovanna del Giudice}

Médica, Psiquiatra, Presidente da Conferenza Permanente per la Salute Mentale nel mondo Franco Baságlia - Trieste/Itália.

Boa tarde a todos.

Primeiro, eu gostaria de fazer alguns agradecimentos e saudações. Em particular, inicialmente, a Sônia Barros que permitiu que eu pudesse participar desses dias, que são dias de encontro, de grande valor, de muito interesse seguido por nós, da Itália, que acompanhamos os processos de desinstituicionalização que aqui aconteceram e continuam a acontecer. Quero agradecer a generosidade da Fernanda que me acompanha na tradução nesses dias. E gostaria também de trazer a saudação de Franco Rotelli, assim como dos colegas e amigos do Departamento de Saúde Mental de Trieste a todos os companheiros e companheiras do Movimento Antimanicomial do Brasil, com o qual nós nos ligamos com tantas pessoas com uma grande amizade.

Eu vou buscar trazer para vocês, de forma sintética, e em certo sentido breve, o processo que está sendo desenvolvido na Itália, principalmente, nos últimos cinco anos e que resultou no fechamento dos hospitais psiquiátricos judiciários. Processo certamente complexo, repleto de obstáculos e dificuldades que, evidentemente, não se conclui com o fechamento dos hospitais psiquiátricos, mas que talvez possamos dizer que ele tem um próprio desenvolvimento a partir do fechamento dos hospitais psiquiátricos judiciários. 
Para dizer para vocês de onde nós partimos. Na Itália, em dezembro de dois mil e onze, existiam seis hospitais psiquiátricos, um dos quais somente para mulheres. Nesses seis hospitais psiquiátricos judiciários estavam internadas mil e quatrocentas pessoas, em dois mil e seis, para contextualizar, a Itália tem sessenta milhões de pessoas, um país que fechou os hospitais psiquiátricos públicos e gerais, gerais no sentido de não serem os judiciários, em mil novecentos e setenta enove.

Eu não farei referências às normativas e à cultura científica que fundem, legitimam os hospitais psiquiátricos judiciários, na medida em que a relatora precedente abordou as normas que fundam os hospitais psiquiátricos judiciários e que podemos perceber a absoluta semelhança entre essas normas e essas culturas na Itália e no Brasil. Podemos sintetizar essas normas na Itália que estão no Código Penal, o Código Penal Italiano, o Código fascista de mil novecentos e trinta, uma pessoa então que cometeu um delito ou um crime é declarada incapaz e lá eles têm essa expressão de "incapaz de compreende e de querer" e ela passa e é tida também como perigosa socialmente, ela vai então ser encaminhada ao hospital psiquiátrico judiciário após ter sido isenta em termos de processo criminal e ela passa pelo percurso totalmente especial em relação às outras pessoas que cometem atos ou delitos em conflito com a lei. Isso significa então que na base da internação do hospital psiquiátrico judiciário tem um duplo trilho, são dois trilhos e ela passa ter um estatuto especial.

Por que eu enfatizo isso como uma questão central? Porque quando a lei cento e oitenta, promulgada em setenta e oito, na Itália, que coloca fim ao estatuto especial do louco e coloca como sujeito, pleno da cidadania social e entra para a cidadania social, desculpe, evidentemente, isso coloca uma evidente contradição com o Código louco. É evidente que após a prorrogação da lei cento e oitenta da Itália nasce um conjunto de propostas feitas por juristas e também por psiquiatras que denunciam a inconstitucionalidade dos hospitais psiquiátricos judiciários e evidenciam a contradição colocada com a prorrogação da lei cento e oitenta.

A Corte Constitucional, daquele período, foi estabelecendo um conjunto de sentenças que fragilizam, mas que de alguma forma não resolvem a questão. Em particular, uma sentença que é publicada logo depois da promulgação da lei cento e oitenta, coloca em discussão e busca superar, colocar um fim nessa conexão entre presunção de periculosidade e doença mental. Portanto, uma pessoa que cometeu um delito e ela foi isenta, ela não pode ser simplesmente encaminhada automaticamente para o hospital psiquiátrico judiciário, a não ser que a sentença aplicada a coloque como perigosa. Ou seja, não tem mais esse nexo automático com a periculosidade da pes- 
soa com transtorno mental. Depois dos anos dois mil, duas importantes sentenças da Corte Constitucional.

A primeira, que reitera que com a promulgação da lei cento e oitenta e da constituição de uma rede de serviços comunitários, declara a ilegitimidade do hospital psiquiátrico judiciário, porque significa produzir uma discriminação na medida em que as pessoas deveriam, pela lei cento e oitenta, serem cuidadas nos serviços do território. Sanciona que, o direito à saúde deveria ser superior, deveria superar o direito de tutela da comunidade. E, portanto, ela coloca que, pessoas com transtornos mentais, que cometeram algum tipo de delito, deveriam ser aplicadas medidas alternativas, que as possibilitassem de serem cuidadas nos serviços da comunidade. Isso permite a alguns departamentos de saúde mental italianos não recorrer mais ao hospital psiquiátrico judiciário, exatamente aplicando essa sentença da Corte Constitucional e trabalhando com a magistratura local, ou seja, isso permite que mesmo com o veto do Código Civil, possa se buscar alternativas que não fosse o encaminhamento a um hospital psiquiátrico judiciário. E assim, do que eu tenho conhecimento tanto em Trieste quanto a Áquila, desde os anos dois mil não se interna mais nenhuma pessoa no hospital psiquiátrico judiciário mesmo na presença do Código, na aplicação da sentença da CorteConstitucional.

O processo de fechamento dos hospitais psiquiátricos judiciários, ele passa a ser desenvolvido a partir de dois mil e oito, quando uma comissão contra a tortura e os tratamentos desumanos e degradantes do conselho da Europa visitam um hospital psiquiátrico judiciário italiano e denuncia ao governo italiano, o estado de atraso e de violação dos direitos humanos das pessoas ali encontradas. A partir então, desse Conselho europeu, o Senado italiano constituiu uma comissão de inquérito, que possibilita intervenção e realização de visitas de inspeção não agendadas em todos os hospitais psiquiátricos judiciários a partir de julho de dois mil e dez. Os senadores então verificam as condições desumanas, degradantes nas quais as pessoas vivem, ou melhor, são constrangidas a viver nos seis hospitais psiquiátricos judiciários e denunciam a situação de degradação, de abandono e de tortura presente nesses lugares. Em particular, é colocada bastante luz, bastante visibilidade à prisão perpétua branca, ou seja, pessoas internadas por trinta, quarenta, cinquenta anos em hospitais psiquiátricos judiciários, pelos mecanismos já aqui apresentados anteriormente, pessoas que cometeram delitos muito pequenos, como por exemplo: furto de uma bicicleta, furto de alguma outra coisa; como aqui temos nessa situação e que passam então a ficar internadas por toda sua vida. Essas visitas de inspeção então da comissão de inquérito produz um vídeo que foi apresentado no Parlamento italiano, que coloca para os senadores a necessidade que 
eles pudessem conhecer as instituições, instituições em relação às quais eles não tinham assumido responsabilidade nem em relação a essas instituições nem em relação à trajetória dessas pessoas. Esse mesmo vídeo foi projetado no circuito de televisão comum, isso significa que não é possível que nenhum italiano diga que não conhece ou que não sabe sobre o horror que são os hospitais psiquiátricos judiciários. Assim, se coloca em movimento um processo legislativo e em fevereiro de dois mil e doze é promulgada uma lei que fixa o prazo de um ano, dois mil e treze, para o fechamento dos hospitais psiquiátricos judiciários. Essa mesma lei coloca que, em cada região italiana, devam ser criadas residências sanitárias onde as pessoas estarão internadas no desenvolvimento, enquanto elas cumprem a medida de segurança, as pessoas que estavam internadas nos antigos hospitais psiquiátricos; assim como aquelas que foram consideradas isentas. Também está previsto por essa lei, a constituição de um orçamento para a construção ou a transformação para a criação dessas residências sanitárias. Nesse mesmo momento, se desenvolve um forte movimento contra essalei.

Um conjunto de associações, dentre elas a Conferência Permanente para a Saúde Mental no Mundo Franco Basaglia, o Sindicato Nacional dos Trabalhadores, o Fórum de Saúde Mental, associações que defendem os direitos dos presos, a partir de uma coordenação comum começam a colocar críticas a essa lei. Essa coordenação comum passa a ser denominada Stop ou Stop HPJ, ou seja, os hospitais psiquiátricos judiciários Stop e faz forte crítica a esta lei no sentido de colocar que o fechamento dos hospitais psiquiátricos judiciários, nessa perspectiva, poderia reconstituir em cada região italiana, nessas residências, novos pequenos hospitais psiquiátricos sem, exatamente, uma transformação dalógica.

Esse conjunto de associações da qual eu faço parte, passa a exercer uma vigilância constante desses processos, desencadeados a partir de dois mil e doze, numa perspectiva de reduzir danos, de tentar buscar melhoras importantes na lei, assim como nas culturas que a sustenta. Esse conjunto de associações torna- se, então, um interlocutor fundamental neste diálogo com o Senado e com a comissão do Senado. No meu ponto de vista, nesse diálogo, esse conjunto de associações pode determinar uma melhora significativa da lei nos anos que se seguiram. O que quero dizer com isso? Nesse processo, se buscou que a ênfase não fosse que a alternativa ao hospital psiquiátrico judiciário fosse colocada nas residências sanitárias, para o lugar por excelência, para a execução para o desenvolvimento das medidas de segurança e passasse a uma ênfase nos percursos terapêuticos reabilitativos, individuais, usando, inclusive as sentenças da Corte Constitucional que eu assinalei precedentemente para se buscar medidas alternativas à detenção. Isso significa, 
portanto, que mais uma vez nós colocamos o foco porque essa passagem deve se dar, não centrada nas instituições, mesmo sendo elas pequenas, mas o foco deve ser o cuidado em liberdade e no território. Como é o momento atual? Ocorreram duas prorrogações do prazo em relação ao fechamento dos hospitais psiquiátricos judiciários e foi definido então um novo prazo de março de dois mil e quinze. Essas prorrogações foram reveladas como necessárias, na perspectiva de efetivamente, é aquela expressão que nós conhecemos de difícil tradução literal: "assumir o encargo", que nós traduzimos para "assumir a responsabilidade pelas mil e quatrocentas pessoas que estavam presentes em dois mil e onze, nos seis hospitais psiquiátricos judiciários".

E isso, através então, dessa possibilidade de assumir a responsabilidade dos serviços de saúde mental e naquelas situações onde não era possível que houvesse então a transferência para essas unidades. E onde estamos hoje? Os dados que apresento são de seis de novembro de dois mil e dezesseis. Foram fechados quatro hospitais psiquiátricos judiciários. Então, isso significa que permanecessem dois hospitais psiquiátricos judiciários abertos, mas para um total de vinte e seis pessoas. Nas regiões italianas foram construídas vinte e seis residências sanitárias, os lugares então para o desenvolvimento da medida de segurança. Com total de seiscentos e dois leitos nas residências, não propriamente leitos, lugares. Foram acompanhadas até agosto setecentas pessoas, mas tiveram alta, aproximadamente quinhentas. Isso significa que teve uma importante melhora no sentido que os dados indicam que diversas das pessoas internadas nos hospitais psiquiátricos judiciários foram assumidas pelos departamentos de saúde mental, mas depois com o processo de transinstitucionalização. E assim, com a melhora da lei, com as leis que prorrogaram os prazos, com investimento desse comitê Stop HPJ, podemos dizer que temos certa superação da prisão perpétua branca, com transformações importantes, porque nenhuma pessoa pode ser mais internada no hospital psiquiátrico judiciário ou em uma das residências, senão pelo mesmo período que outra pessoa que não tenha transtorno mental da pena que ela cumpre.

Outro dado importante é que essas estruturas regionais das residências são heterogêneas, elas apresentam diversas diferenças em termos de organização e funcionamento. Isso significa, esta heterogeneidade, essa diferença, que não tem exatamente uma regulamentação, mas que também coloca a possibilidade de que essas residências possam ser superadas. De alguma forma, o momento atual é de Stop Residências Sanitárias, para que seja efetivamente assumida a responsabilidade das pessoas que cometerem conflito com a lei, pelos departamentos de saúde mental. E isso significa que nos próximos dias, talvez agora já em dezembro, vai fechar mais um hospital psiquiátrico judiciário, perma- 
necendo apenas um, mas apenas com dez pessoas e isso significa que daqui alguns meses nós poderemos dizer que, na Itália, não haverá mais essa instituição total aberrante que é hospital psiquiátrico judiciário. E isto me parece muito importante, mas evidentemente, devemos continuar a investir para a superação desse trilho duplo, ou seja, desse estatuto especial para pessoas com transtornos mentais em conflito com a lei. Isso significa que reinstituir o direito à responsabilidade, o direito que essas pessoas possam vivenciar o processo. Devemos colocar em crise até a superação, as normas de periculosidade social. Nós sabemos que esse é um processo longo e difícil, mas nós sabemos que a desinstitucionalização é contínua e, portanto, mesmo quando nós superamos ou fechamos as instituições, nós devemos continuar a colocar em discussão e superar as normas e a cultura que a sustenta. Uma última questão, eu estou participando, fazendo uma visita na qualidade de participante do comitê Stop HPJ em todas essas residências sanitárias. O que me parece mais importante nessas visitas é verificar que os operadores que estão nessas residências, que foram ao encontro dessas pessoas que cometeram delitos, eles estão claramente colocando que não é necessário, estruturas especiais, dedicadas a essas pessoas, porque elas são como todas as outras pessoas, que estão presentes também nos centros de saúde mental e aquilo que é necessário é o cuidado em liberdade, é a garantia do direito à atenção e não à segregação.

\section{Programa de atenção integral ao louco infrator (PAILI) - Dr. Haroldo Caetano da Silva}

Promotor de Justiça do Ministério Público do Estado de Goiás, Premiado pelo Instituto Innovare, em 2009, como vencedor do VI Prêmio Innovare, na categoria Ministério Público, com o Programa de Atenção Integral ao Louco Infrator (PAILI).

Boa tarde, gente.

Eu acredito que a responsabilidade é muita, eu vou falar por último. A responsabilidade é grande por falar por último, mas não é uma coincidência. Porque de imediato eu já digo para vocês algo que talvez possa parecer um tanto quanto ousado.

Mas o fato é que Goiás alcançou em 2006 aquilo que a Itália ainda não alcançou. Goiás alcançou em 2006 erradicação do manicômio judiciário. Quem está falando aqui é promotor de justiça, mas é um promotor de justiça que há vinte anos, na verdade a vinte 
e um, está atuando na execução penal. Então, deixa eu só situar para aqueles que não me conhece. Em 95 eu assumi uma promotoria em Goiânia, na execução penal, e comecei a lidar com essa matéria logo de início, em outubro de 2005. Até que rapidamente, já em março, 96 aconteceu um fato, um fato que é muito marcante e eu faço questão de registrá-lo aqui.

É que em março de 2006, quem é mais velho vai se lembrar, houve uma grande rebelião na maior penitenciária do estado de Goiás, o CEPAE. E, naquela ocasião, foram feitos muitos reféns, autoridades públicas, juízes, até o secretário de segurança pública estava entre os reféns, o presidente do Tribunal de Justiça estava entre os reféns e este promotor que vos fala também. Fiquei uma semana dentro da cadeia como refém numa rebelião, assim, muito complicada como qualquer rebelião costuma ser, não é? Naquela ocasião eu me deparei com a população carcerária e lá dentro, também funcionava um manicômio judiciário.

Os pacientes em medida de segurança estavam, também, dentro da maior penitenciária do estado de Goiás. E desde então, é que a gente vem trabalhando esse tema. Em 96 aconteceu esse fato, o PAINI, o Programa de Atenção Integral ao Núcleo Infrator vai nascer dez anos depois em 2006. Estou abreviando bastante a história, evidentemente. Essa rebelião tem, como eu sobrei para contar a história, ela tem muitas boas histórias também, mas vai ficar para uma outra ocasião para a gente falar um pouco disso. Primeiro é importante frisar uma coisa, nós estamos falando aqui é de uma coisa, porque o manicômio nos é apresentado como uma coisa dada, como algo natural, não é? Como se fosse algo de fato essencial para a existência, para a coexistência social. Quando, de fato, ele não passa de um instrumento de controle, não é? Dentro de uma política nefasta de gestão da miséria, para a qual sobra normalmente esses dispositivos que estão aí na tela.

Aliás, faço um registro por importante que a desumanização do delinquente, seja ele quem for, inclusive o louco, ela já começa no ato da detenção pela polícia, o sujeito é colocado dentro do porta- malas de uma viatura policial e isso é visto também como uma coisa absolutamente normal, pela nossa sociedade. E nós acabamos por reproduzir e reforçar esse conceito, esse conteúdo que representa de fato a desumanização, não é? Você retira a condição de pessoa e a partir desse momento, dela lhe são tirados direitos como nós vemos acontecer dentro do presídio, dentro do manicômio, dentro dos diversos dispositivos de instituições de controle.

Nesse espaço qual é o lugar do louco? Dentro da sociedade capitalista, fora das relações produção e consumo, qual é o lugar da miséria? Qual é o lugar do louco? 
Então é disso que nós estamos falando. Nós precisamos nos localizar porque trata-se de fato de um dispositivo, o manicômio judiciário, um dispositivo de gestão da miséria. Quem conhece o manicômio judiciário vai perceber rapidamente lá dentro que são todos pobres, eu conheci muitos manicômios pelo Brasil. E de fato jamais encontrei alguém em boa condição socioeconômica que estivesse internado, internado é eufemismo, não é? Que estivesse preso em manicômio judiciário. Mas essa figura vem daquilo que já foi falado nas outras mesas, dessa disputa de uma legislação de 1940 com a legislação de 2001, que é a lei antimanicomial.

Estou falando rápido porque eu quero falar, passar todo o conteúdo, quero tentar ser o mais claro possível, mas sem perder o conteúdo daquilo que me propus a dizer aqui para vocês.

Ultimamente, no Brasil nós temos por banalizada a expressão fascista. Por conta da divisão da sociedade nessa disputa, enfim, que nos coloca em lados opostos, às vezes até dentro de casa com os nossos irmãos, com os nossos amigos, não é? Quem não tem tio 'reaça' por aqui ou quem, quem é ou é 'reaça' e não tem um tio 'petralha'. Então isso é um fato, não é? Mas se tem algo que você pode, a professora Giovanna não me deixa mentir, pelo que ela já disse agora há pouco, se tem algo que é essencialmente fascista, eminentemente fascista e está lá na legislação brasileira é a medida de segurança. A medida de segurança não tenho medo de dizer, é um dispositivo fascista, ele vem para o Brasil inspirado, como a professora Giovanna deixou claro na fala dela também, no Código Roco, no código fascista italiano, e em 1940 nós copiamos essa disposição. Até então a pessoa que era considerada inimputável, ou seja, sem responsabilidade penal, era simplesmente absolvida, mesmo que fosse louca, não ia para manicômio judiciário. Havia outros dispositivos, é verdade, mas do ponto de vista jurídico penal ela não era submetida a essa estrutura, a essa instituição total do manicômio. Que se baseia, como já foi falado muitas vezes aqui, não vou repetir, na periculosidade de pretensão. Na pretensa periculosidade do louco, não é? Que aliás, periculosidade era algo que tinha um alcance muito maior daquilo que a gente poderia imaginar.

Hoje, olhando com olhar de 2016 para 1940 vocês vão ver hoje um certo ridículo no conteúdo da norma. Porque em 1940, com a legislação de então, era perigoso até o sujeito que viesse a ser condenado, digamos, por dois crimes de furto. A reincidência, por si só, implicava naquele sujeito a condição de perigoso. E, além da pena, ele era submetido também à medida de segurança. Isso mudou em 1984, com a reforma penal, nós deixamos o duplo binário e passamos assumir no Brasil o que o direito penal estabelece como sistema diferente. Onde somente se aplica pena ou medida de segurança, não as 
duas coisas ao mesmo tempo. De forma então, que o sujeito que é responsável, digamos aquele ladrão do furto que mencionei, ele vai ser submetido a uma sanção penal e vai para a prisão. Ao passo que o louco não, ele não é submetido à prisão, mas é submetido apenas a medida de segurança. Então separou-se, em 1984, essa questão. Entretendo, aí é importante mencionar também que lá em 84, diferentemente de 40; lá em 1940 a medida de segurança era essencialmente uma sanção, uma punição do louco. Era vista como algo de natureza sancionatória, punitiva, a medida de segurança aplicável ao louco. Em 84, pelo menos do ponto de vista da norma, o código penal passou a falar em tratamento, no artigo 98 do código penal.

A medida de segurança então devia ser, não mais uma sanção, mas era tratamento. Ocorre que o mesmo código penal, aliás, só para não ficar sem explicação, eu coloquei algumas ilustrações, mas são meras ilustrações mesmo, não tem às vezes relação direta com o conteúdo do slide. Aí nesse caso até nessa foto está de cabeça para baixo, foi uma visita que eu fiz lá no manicômio judiciário de Franco da Rocha, aqui pertinho. Vocês podem observar que eu estava com esse mesmo paletó que é o único paletó que resiste ao frio de São Paulo, para vocês verem que está sempre guardadinho. (Eu venho com alguma frequência a São Paulo.) Mas o código penal ainda definido como tratamento, ainda assim estabelecia que a medida de segurança seria aplicada não segundo a necessidade clínica, a internação ou o tratamento ambulatorial seriam utilizados não pela necessidade clínica, mas sim pela natureza do crime, a natureza da pena culminada ao crime. Se o crime era punível com reclusão, internação do sujeito.

Acontece que no Brasil quase tudo é punível com reclusão, até uma tentativa de furto de uma geladeira, o louco tenta carregar uma geladeira de um supermercado, vai ser preso, evidentemente. Nesse caso ele vai ser submetido a uma internação não porque ele precisa, do ponto de vista terapêutico, de uma internação, mas porque a norma define que o crime de furto é punível com reclusão. Então, a regra geral passa a ser a internação para todo mundo, e a medida de segurança ficava então vinculada a uma sensação de periculosidade, disso que nós já falamos, desse conceito absurdo. Vou falar um pouco mais sobre ele daqui a pouquinho também.

E o paciente vai para o HCTP, que é o hospital psiquiátrico judiciário da Itália e que aqui é o nosso manicômio judiciário. HCTP é um nome bonitinho, é uma sigla para o nome bonitinho de Hospital de Custódia e Tratamento Psiquiátrico, que é um belo de um eufemismo para prisão do louco. Essas fotos eu fiz questão de colocar, porque eu fiquei muito impressionado quando eu visitei esses lugares. Essa, deixa eu ver se aqui tem aquela luzinha, essa foto maior, a resolução não está boa, é um manicômio aqui de São 
Paulo que fica lá na cidade de Casa Branca. Esse corredor que atravessa os pavilhões tem 700 metros de cumprimento, para vocês terem uma noção do tamanho que é aquiloali.

No passado era outra coisa, era utilizado para outro público, mas hoje é um manicômio judiciário. O outro manicômio eu coloquei mais pela curiosidade, porque ele é o complexo médico penal de Curitiba. Vejam que ele, a estrutura original dele é essa estrutura central que tem formato de um fuzil.

A arquitetura projetou um manicômio judiciário no formato de um fuzil, bem apropriado, evidentemente. Mas o HCTP o quê que ele é? Ele é aquilo, no que couber, equivalente a uma cela. E o quê que é uma cela? É um lugar onde se colocam, onde as pessoas que são condenadas são presas, não é? E assim como o condenado, o paciente em medida de segurança lá no manicômio judiciário, no HCTP, é colocado também nessa estrutura celular que nós sabemos muito bem que os presídios, os manicômios são presídios apenas com outro nome, e que recebem os mesmos, têm praticamente as mesmas características. Aliás, são até instituições que normalmente são cuidadas ou geridas, melhor dizendo, cuidadas nunca são, são gerenciadas pela administração penitenciária dos estados.

Acontece que em 1988 veio a Constituição e estabeleceu textualmente o direito penal da culpabilidade. O quê que é isso, de onde isso vem? Um dispositivo da Constituição que diz que nenhuma pena passará da pessoa do condenado. O quê que isso quer dizer em outras palavras? Que para que alguém seja submetido a uma sanção penal, a um dispositivo punitivo, castigo, portanto, ele precisa ser declarado culpado, ele tem que ser condenado na sentença penal. E essa condenação pressupõe culpabilidade, e o louco não é culpável, justamente por conta da não responsabilidade penal que o código penal define. Ele é imputável porque não conhece o caráter ilícito do fato ou não consegue se determinar de acordo com esse entendimento. Não tem responsabilidade penal, se não tem responsabilidade penal ele não tem culpa, se ele não tem culpa, ele não pode ser condenado, se ele não é condenado ele não pode ser submetido a uma sanção penal.

A sanção penal por manicômio, então, foi retirada pela Constituição de 88. Não mais persiste a natureza sancionatória da medida de segurança, aquela lá do código fascista de 1940. Nenhuma pena passará para a pessoa do condenado. Isso significa que para alguém ser preso no Brasil ele precisa ser submetido a um processo, precisa ser condenado nesse processo. E o louco, quando ele é submetido a um processo ele é absolvido no processo. Ah, mas ele praticou um homicídio grave, um estupro, um latrocínio, um crime cruel, não interessa. Do ponto de vista jurídico penal ele é inocente, se o sujeito é inocente ele é absolvido. Ah, mas ele é perigoso, aí é uma outra questão que nós vamos discutir um pouquinho. 
A Lei de 2001 todo mundo aqui já leu, com certeza, mais de uma vez, mas ela vem e passa a não deixar nenhuma dúvida quanto ao tratamento que deve ser dispensado a qualquer pessoa com transtorno mental. Qualquer pessoa com transtorno mental submetida a qualquer tipo de tratamento psiquiátrico deverá receber o tratamento regulado na Lei 10.216, que se funda na liberdade do sujeito, não é? E eu destaco esses dispositivos porque eles, a gente precisa registrar esses dispositivos e nos assenhorar desses dispositivos para aplicá-los também nos manicômios judiciários que eles estão funcionando no Brasil, e não são poucos.

O Censo de 2011, feito pela Débora Diniz por encomenda do Ministério da Justiça, registrou quase 4 mil pessoas internadas em manicômios naquela ocasião. A internação, em qualquer de suas modalidades, só será indicada quando os recursos extra hospitalares se mostrarem insuficientes. Então de cara você já tem aí uma norma que modificou o código penal. Então, o sujeito lá do código penal que praticou o crime ele não vai ser levado a uma internação psiquiátrica porque praticou um crime de furto ou porque praticou um crime de homicídio ou porque um estupro, isso é indiferente. O que vai determinar o tratamento pelo regime de internação é o quê? A necessidade clínica, a necessidade terapêutica para esse paciente. Quem vai dizer isso? A equipe de saúde, não é? Que atende, que acompanha esse sujeito. Até porque, e é bom fazer esse registro, digamos num crime de homicídio, o homicídio aconteceu há um ano e meio atrás num momento em que o sujeito estava em crise, em surto psicótico. Naquele momento talvez ele precisasse de uma internação, provavelmente sim. Hoje, passados um ano e meio, ele precisa de internação? Muito provavelmente não, mas se ele precisar isso poderá ser utilizado, mas a realidade, a necessidade clínica deste ou daquele recurso terapêutico é identificada agora. E não vai ser uma sentença, que dista tanto tempo assim do fato, que vai determinar o melhor tratamento. $O$ tratamento visará como finalidade permanente a reinserção social do paciente em seu meio. Se tem algo que rompe com qualquer laço social é uma internação, e uma internação manicomial rompe quase que definitivamente os laços familiares e sociais.

Não é só na Itália que tem paciente com 40 anos em medida de segurança, aqui também temos gente nessa mesma condição, internada em diversos manicômios pelo país. Então o manicômio vai contra esse dispositivo. Diferentemente da internação manicomial, nós temos que usar outros dispositivos que busquem esse objetivo que é obrigatório, esse é um objetivo fundamental no atendimento à saúde mental. Mas, tão importante quanto isso é o parágrafo $3^{\circ}$, que para qualquer entendedor, não precisa ser jurista, é claro, é de uma clareza solar que quase nos cega. "É vedada a internação 
de pacientes portadores de transtornos mentais em instituições com características asilares".

Quer algo mais claro do que isso? A internação asilar está proibida no Brasil desde 2001, 15 anos. Há 15 anos a porta de entrada do manicômio judiciário está fechada, do ponto de vista da norma. Não dos aplicadores da norma, mas do ponto de vista da Lei, quer algo mais claro do que essa disposição? E o quê que tem característica asilar por excelência nesse espaço que seja mais asilar do que um manicômio judiciário? Como já foi dito aqui, o professor já no início falou, que é aquilo que é o limite do limite onde a lei ainda não teria chegado, evidentemente aonde funciona o manicômio judiciário, não é o caso do meu Estado. Mas é o que acontece aqui em São Paulo e em praticamente todo o país.

Mesmo em Minas Gerais, que tem brilhante programa, que é precursor ao nosso, inclusive, mesmo com todo o esforço e empenho dos profissionais do PAEPJ e a dedicação e a qualidade dos serviços são que oferecidos pelo PAEPJ, muito bem apresentado aqui pela Professora Romena, Minas tem uma tradição manicomial pesada, são três manicômios judiciais em plano funcionamento em Barbacena, em Juiz de Fora e em Ribeirão das Neves. O que me permite dizer então? É que Juiz de Fora está sendo fechado. Eu quero ver a notícia dele estar fechado, ainda. Mas o que se tem então é que há uma ilha antimanicomial, num mar de manicômios que é o país inteiro, manicômios judiciais. $\mathrm{E}$ nós precisamos de fato enfrentar essa questão, é para isso que estamos tentando dialogar, aquitambém.

Ambiente manicomial prevê uma série de dispositivos e direitos da pessoa com transtorno mental e eu registro aí ressalva de alguns deles. Primeiro para dizer que a internação, em qualquer das suas modalidades, será sempre um dispositivo de saúde. Então, se aquele sujeito está incomodando na rua o vizinho, isso não é problema de saúde, isso é um problema de convivência entre os sujeitos. Se, o sujeito está, enfim, não é um dispositivo de segurança pública. Internação é um dispositivo de saúde. Deixa eu voltar nessa imagem porque não tem como não falar, o que de mais lindo aconteceu nos últimos quinze anos, não é?

No campo da reforma psiquiátrica foi produzido pelos usuários, pelos usuários não, pelas vítimas do manicômio judiciário de Franco da Rocha. O que de mais belo aconteceu aí foi agora, há um pouco mais de um mês. Em que os pacientes do manicômio judiciário de Franco da Rocha fugiram, não é? Na cela foi a imagem com pouca resolução, mas tem gente lá no, fugido lá em cima do morro escapando do manicômio de Franco da Rocha e lá embaixo o manicômio destruído. O manicômio é algo tão 
ruim, mas tão ruim, nós não sabemos disso, mas os loucos sabem tão bem disso que eles não querem o manicômio não é para eles não, não querem para ninguém, fogem e põe fogo no que ficou. E a internação psiquiátrica, vão dizer: "Ah, mas essa lei não se aplica”, aplica sim. Lá no artigo $6^{\circ}$, parágrafo único, inciso $3^{\circ}$, a lei se aplica a qualquer tipo de internação, inclusive a compulsória, que é a determinada pela justiça. É a única internação compulsória que existe na nossa legislação é feita em medida de segurança. E ainda assim deve obedecer aos dispositivos da lei 10.216. Tem que ser excepcional, tem que ter objetivo de reclusão social, tem que ser, enfim, obedecer a todos aqueles recursos que são definidos no artigo $2^{\circ}$ como direitos da pessoa com transtorno mental, dentre um milhão de outras questões que eu não vou poderfalar agora. Enfim, o manicômio tornou-se uma instituição ilegal, e essa foto eu recebi na semana passada em um evento do qual participei em Curitiba. Alguém aqui, estava naquele evento? Não? Mas na semana passada eu estive num evento sobre saúde, desintitucionalização em Curitiba, essa foto que me foi trazida por uma juíza. E essa pessoa se chama, é uma mulher se chama Marisa, está há 23 anos, não está há 23 anos internada, ela está no manicômio judiciário de Curitiba há 23 anos com ordem de soltura. Há 23 anos ela recebeu ordem de liberação do manicômio judiciário. Mesmo com ordem judicial de liberação do manicômio judiciário, há 23 anos ela continua lá. Isso vai nos levar a uma outra questão que eu quero falar rapidamente aqui, porque eu estou pressionado pelo tempo. Mas vamos voltar nela daqui a pouquinho. Isso significa então, que a legislação, e eu estou falando de tudo isso aqui, eu estou falando, ao falar de tudo isso aqui eu estou falando do Programa de Atenção Integral ao Louco Infrator. É com base nessa perspectiva toda é que nós instituímos lá essa figura antimanicomial por excelência que aboliu a possibilidade da internação asilar, da internação em manicômio judicial fundamentalmente. A porta de entrada está fechada em 2001, do ponto de vista da norma, o PAI é o primeiro a fechar efetivamente isso em 2006, foram cinco anos depois. A porta de saída está aberta, mas não é para sair de qualquerjeito.

Há quinze anos ela deveria estar sendo trabalhada, visando a obra planejada e a reabilitação psicossocial assistida. Está lá no artigo $5^{\circ}$ da Lei antimanicomial. Um pouco, esse slide anterior falava desse conceito jurídico da periculosidade, não é? Que a medicina trouxe para si e criou a figura do louco perigoso que não observa nem princípios fundamentais do direito penal nem princípios fundamentais da medicina. Louca, na verdade, é a figura da periculosidade que ali foi estabelecida. Mas eu não vou ficar, não vou me ater a isso. Não se fala mais em periculosidade, qualquer tratamento em saúde mental visa a reinserção, não há outro objetivo a ser alcançado no tratamento em saúde mental. Mesmo para aqueles, mesmo que praticou um crime grave. 
O tema sai da esfera da segurança pública, passa a ser trabalhado na esfera da saúde pública. O PAILI em Goiás é um programa que funciona, não é lá do Ministério Público, não é do Poder Judiciário, é um programa da Secretaria de Estado da Saúde. Vou falar um pouquinho da estrutura dele rapidamente daqui a pouco. Eu coloquei a ilustração, eu coloquei o Belchior e o Raul Seixas aí porque são poetas, não é, que levam para a poesia essa inquietação diante da loucura. Para ficar só um registro rápido aqui: "A minha alucinação é suportar o dia a dia, e o meu delírio é a experiência com coisas reais" Belchior, não é? E eu gosto muito de meu amigo, meu amigo Pedro, do Raul Seixas. E ele conversa com Pedro, não é, autoral: “Cada um de nós é um universo (............) deixa eu viver a minha loucura”. Enfim, são poetas quetrazem essa coisa mais sensível para a questão da loucura. Tudo isso aí dá fundamento ao PAILI, o Programa de Atenção Integral ao Louco Infrator que funciona em Goiás e nos rendeu o prêmio INOVARE como já foi falado aqui, lá em 2009.

Aqui são algumas reuniões que foram feitas lá.

Como funciona isso aí? Vou tentar ser breve... Rotina: como é que funciona isso? Bom, lá não tem manicômio, como é que as pessoas são encaminhadas nesses, a partir do momento que são submetidas à uma medida de segurança? A sentença aplicou medida de segurança, o caso é estudado pelo PAILI que vai indicar qual será o melhor dispositivo de saúde a ser utilizado naquele caso, a internação será sempre excepcional. Nós veremos daqui a pouco nos dados estatísticos. Então a tarefa ambulatorial tem sido a regra, e o paciente vai para o tratamento ambulatorial. Eventualmente o PAILI vai buscar o paciente dentro da casa de prisão provisória, ele está preso provisoriamente. Sai a sentença, o PAILI busca o paciente lá e vai fazer o estudo e inseri-lo no melhor dispositivo da rede. Nós não falamos em periculosidade, falamos em avaliação psicossocial. Eu não quero saber se o sujeito é perigoso, essa coisa estranha que não tem fundamento algum, a não ser do mito. Eu quero saber se ele trabalha, se ele tem filho, se ele tem família, se ele tem condições de se manter, enfim, até para se conhecer a sua realidade psicossocial para saber também qual é a necessidade que ele vai precisar, o apoio que ele vai precisar para se tratar, para ser acompanhado. Aí isso acontece até que ele venha ter a liberação condicional, que é normalmente depois de um ano, e a medida de segurança é extinta. Isso tudo funciona, eventualmente o paciente que está em medida de segurança lá em Goiás passa por um surto psicótico, aliás, como qualquer pessoa que é atendido na rede de saúde mental eventualmente vai passar, pode passar. O que fazer nesse caso? Ele vai ser internado. Vai depender de ordem judicial para ser internado? Não, vai ser internado até que haja a, enquanto houver essa necessidade clínica, mas 
a partir do momento que houver a alta, não houver mais a necessidade terapêutica da internação, ele vai sair, ele não vai depender de juiz para fazer isso, o PAILI resolve tudo isso. Ele apenas faz comunicações periódicas ao judiciário.

Para fechar, aqui alguns dados.

Em dez anos de funcionamento, 554 casos acompanhados. A nossa população em Goiás é de um pouco mais de 6 milhões e meio de habitantes. Usuários em atendimento hoje 341, alguns tiveram a medida extinta, outros morreram, e tem situações das mais variadas, hoje são 341 em acompanhamento. Internações, esses dados são de anteontem, são oito, anteontem nós tínhamos oito pacientes internados em todo o estado de Goiás, internados em leitos do Sistema Único de Saúde. Não é internado em manicômio ou coisa que o valha. A reincidência gira em torno de $5 \%$ dos quais em dez anos houve dois crimes graves. Então 5\% de 500 casos, vamos arredondar, 35 episódios de reincidência, a maioria em crimes leves e dois episódios de crimes graves, um deles, inclusive, com grande repercussão até nacional.

A cobertura do programa é total, ele cobre todo o território do estado de Goiás, sem exceção. De forma que qualquer pessoa que for sentenciado em qualquer lugar do estado vai ser encaminhado ao PAILI se for submetido à medica de segurança para ser colocado onde? Num determinado lugar? Não, para ser colocado que é a casa dele, não é? E para se dar início ao trabalho que deve ser feito de acompanhamento nesses casos. Há um dado importante, vou também frisar aqui, o tamanho da equipe, uma equipe de quinze funcionários entre servidores administrativos e equipe técnica, atende toda a população em medida de segurança do estado de Goiás. Imagine então o custo financeiro de tudo isso aí, não é? Irrisório. Ele usa, faz uso da rede de apoio do SUS, da RAPS, evidentemente, mas tem sido muito importante, tem sido interessante demais o quanto tem sido fundamental o apoio da atenção primária à saúde nesses casos. Então, tão importante ou às vezes até mais importante do que um CAPS na cidade, às vezes, é ter um dispositivo potente da estratégia de saúde da família. Porque o paciente não é visto apenas como cabeça, não é? Como um problema mental, um problema de saúde mental. É visto como uma pessoa, como um cidadão que tem, enfim, diversos tipos de encaminhamento, eventualmente isso não ultrapassa única e simplesmente a atenção do sistema de saúde.

Tem alguns dados sobre a rede de Goiás, bom, é mais ou menos isso. O PAILI funciona dentro da estrutura, digamos, administrativa da Secretaria de Estado de Saúde, tem a secretaria, tem a superintendência, tem a coordenação de saúde mental, a gerência de saúde mental, ele é uma coordenação dentro da gerência de saúde mental. Não é saúde 
prisional, observe esse detalhe importante, é uma estrutura dentro da secretaria da saúde na gerência de saúde mental. O que, e a partir dali ele é um escritório que faz com que seja articulado toda a rede de atenção psicossocial, assim com a atenção primária, eventualmente como é chamada a dar esse suporte. E a partir dessa equipe se faz com que essa população de medida de segurança seja contemplada sem qualquer utilização da internação asilar. Aí tem alguns dados de contato para quem quiser, o e-mail está aí. Era isso mesmo, muito obrigado a todos. 